\title{
影响染色体三维结构的主要因素及其研究进展
}

\author{
焚逸仙 ${ }^{1,2}$, 杭晓弯 ${ }^{1,2}$, 何西沝 ${ }^{1,2 *}$ \\ 1. 华中科技大学同济医学院基础医学院生理学系, 武汉 430030; \\ 2. 华中科技大学同济医学院基础医学院基因组与蛋白质组研究中心, 武汉 430030 \\ *联系人, email: XimiaoHe@hust.edu.cn \\ 收稿日期：2019-12-06; 接受日期：2020-01-23; 网络版发表日期：2020-04-15 \\ 华中科技大学人才引进基金(批准号: 3004510109)资助
}

\begin{abstract}
摘要染色体的三维结构与基因表达的精准调控密切相关, 染色体空间结构的改变也常会影响细胞中多种生物 学活动的有序进行. 近年来, 染色质空间构象捕获技术和测序技术的发展, 使得三维基因组学的研究取得一系列 进展. 科学家们发现, 染色质逐级折叠压缩, 具有严密的层级结构, 而影响染色质三维结构的因素则涉及DNA序列 和蛋白复合体等多个方面. 本文综述了影响三维基因组结构的主要因素, 包括一维基因组层面上的DNA序列及其 共价修饰、与基因结构以及顺式调控元件相互作用的蛋白复合体、核小体排布与组蛋白修饰以及在有丝分裂和 染色体多倍化等过程中特有的三维结构变化等多个方面. 通过总结这些因素如何影响染色体的三维结构以及相 关的研究现状, 揭示了染色体三维结构研究的重要作用。本文还简要总结了三维基因组学研究所面临的主要问 题, 并据此展望该领域将来的主要研究方向和可能的应用前景.
\end{abstract}

关键词 三维基因组学, 染色质空间结构, 基因转录调控, 表观修饰, 有丝分裂

生命体是一个高度复杂而又受到精确调控的系 统，而调控这些生命活动的最重要的载体就是细胞内 的遗传物质一DNA. 在真核生物中，DNA并非线性 排列，而是经过逐级折叠成为高度压缩的染色体结构, 并存储在细胞核中. 以人为例，一个体细胞的基因组 DNA展开后的线性长度约 $2 \mathrm{~m}$, 而绝大多数细胞的细 胞核直径不足 $10 \mu \mathrm{m}^{[1]}$. 生物学家一直好奇: DNA是如 何逐级折叠压缩的？在这个高度压缩并且动态变化的 狭小空间中，DNA所承载的遗传信息如何有效传递给 RNA并指导蛋白质翻译的? DNA在各种细胞核内是否 有独特的时空结构，而该结构与细胞命运决定、生长 发育等生命活动的精确调控又是什么关系?
数十年来, 生物学家们一直试图揭开这些谜团. 直 于技术的发展, 早期的研究主要集中在一维(线性基因 组序列，基因及其调控单元的注释等)和二维(不同基 因组序列之间的相互作用)基因组的层面上 ${ }^{[2]}$. 随着人 类基因组计划(Human Genome Project, HGP ${ }^{[3]}$ 和“人 类基因组百科全书计划”(Encyclopedia of DNA Elements, ENCODE $)^{[4]}$ 的完成, 科学家们意识到, 仅从一 维和二维的层面, 并不能完整解释细胞的基因转录等 生命活动的调控. 必须在一维基因组序列及其基因结 构等的基础上，考虑基因组的三维空间结构，研究基 因组的这种三维空间结构如何对基因表达进行调控, 这就构成了三维基因组学的主要研究内容 ${ }^{[2]}$.

引用格式: 樊逸仙, 杭晓亦, 何西永. 影响染色体三维结构的主要因素及其研究进展. 中国科学: 生命科学, 2020, 50: 465-483

Fan Y X, Hang X Y, He X M. The impact factors of 3D genome organization (in Chinese). Sci Sin Vitae, 2020, 50: 465-483, doi: 10.1360/SSV-20190218 


\section{1 三维基因组学研究现状简介}

得益于染色质空间构象捕获技术和测序技术的发 展, 三维基因组学的研究取得了巨大的进步. 染色质构 象捕获(chromosome conformation capture, $3 \mathrm{C}$ ) ${ }^{[5]}$ 以及由 3C发展而来的环状染色质构象捕获(circular chromo-

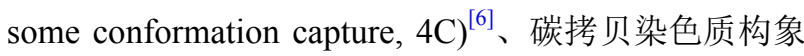
捕获(chromosome conformation capture carbon copy, $5 \mathrm{C})^{[7]}$ 、高通量测序技术结合染色质构象捕获(highthroughput chromosome conformation capture, Hi$\mathrm{C})^{[8]}$, chromatin interaction analysis by paired-end tag sequencing(ChIA-PET $)^{[9]}$ 和Capture-HiC ${ }^{[10,11]}$ 等技术手 段的出现，使人们可以从一个全新的视角和更精细的 分辨率来探索基因组在细胞核内的空间结构. 在人等 哺乳动物的细胞核中, 染色质逐级折叠压缩, 具有严 密的层级结构. 按照结构单元大小和分辨率主要分为 4个层级：染色体疆域(chromosome territories, $\mathrm{CTs})^{[12,13]}$ 、区室(chromatin compartments) ${ }^{[8]}$ 、拓扑相 关结构域(topologically associated domains, TADs) ${ }^{[14]}$ 及染色质环(chromatin loops, CLs)(图1) ${ }^{[15]}$. 从染色体 疆域到染色质环, 层级结构单元逐层缩小, 而染色质构 象的分辨率则从 $\mathrm{Mb}$ 级精确到 $\mathrm{kb}$ 级，逐层放大.

染色体疆域是最早被发现并且普遍存在的基因组
空间结构, 每条染色体在细胞核内都具有其特定的 CT, 而不同染色体之间的CT仅在边界有重叠，从而保证每 个CT相对独立而又能够与其他 CTs 发生相互作用 ${ }^{[16]}$. 每个CT会被进一步分隔成两种不同的染色体区室：以 常染色质为主的活跃区室 $\mathrm{A}($ 染色质常为开放，基因表 达处于激活状态等)和以异染色质为主的非活跃区室 $\mathrm{B}$ (染色质常为关闭, 基因表达处于抑制状态等). 需要指 出的是, 区室A与区室B之间并非一成不变, 在一定条 件下, 一些区室可以相互转化而形成动态平衡 ${ }^{[17]}$. 当 使用Hi-C等技术将区室内的染色质分辨率进一步提高 到 $40 \mathrm{~kb}$ 时，高度自我相关的染色质区域形成TADs(图 2 ), 这些结构域具有 TAD内增强子与靶基因相互作用 强, TAD间相互作用弱的特点 ${ }^{[14]}$. 进一步细分 TAD来 研究sub-TAD间的动态变化时发现, 启动子与增强子 往往可以在相关辅助因子的作用下形成染色质环, 该 环与基因表达密切相关，是基因调控最精细的结构和 功能基本单元 ${ }^{[18]}$. 通过以上各层次的基因组三维结构 折叠, 原来距离较远的线性DNA序列在染色体三维构 象上可能变得相距很近, 从而进行远距离调控.

染色质三维结构对DNA复制、基因的表达调 控、细胞分化及发育等过程具有重要意义 ${ }^{[19]}$. 在从配 子到合子直至发育成生命个体的过程中，染色体的三
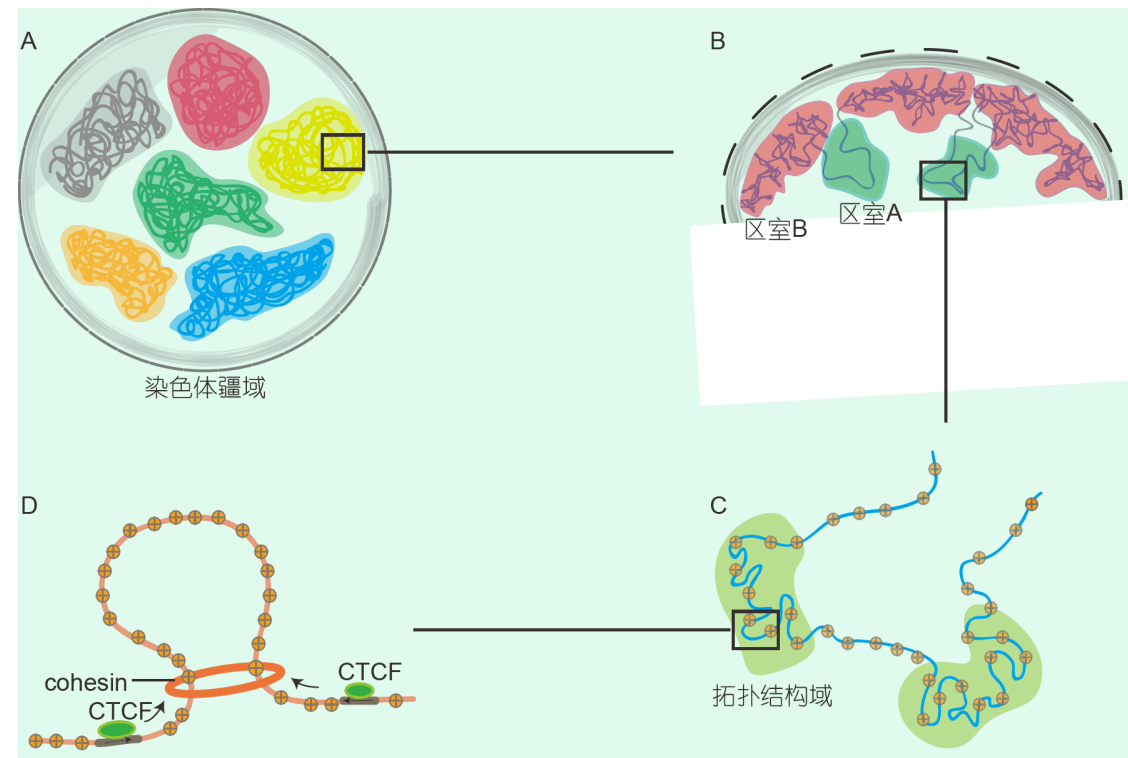

染色质环

拓扑结构域

图 1 染色体三维结构层级. A: 染色体疆域; B: 区室A和区室B, 区室B倾向靠近核膜的位置; C: 拓扑结构域; D: 染色质环, 从A 到 $\mathrm{D}$ 分辨率逐渐提高

Figure 1 3D hierarchical structural units of chromosomes. A: CTs; B: compartment A/B, compartment B tends to be localized close to nuclear membrane; C: TADs; D: chromatin loops, the resolution has been gradually improved from panel A to D 


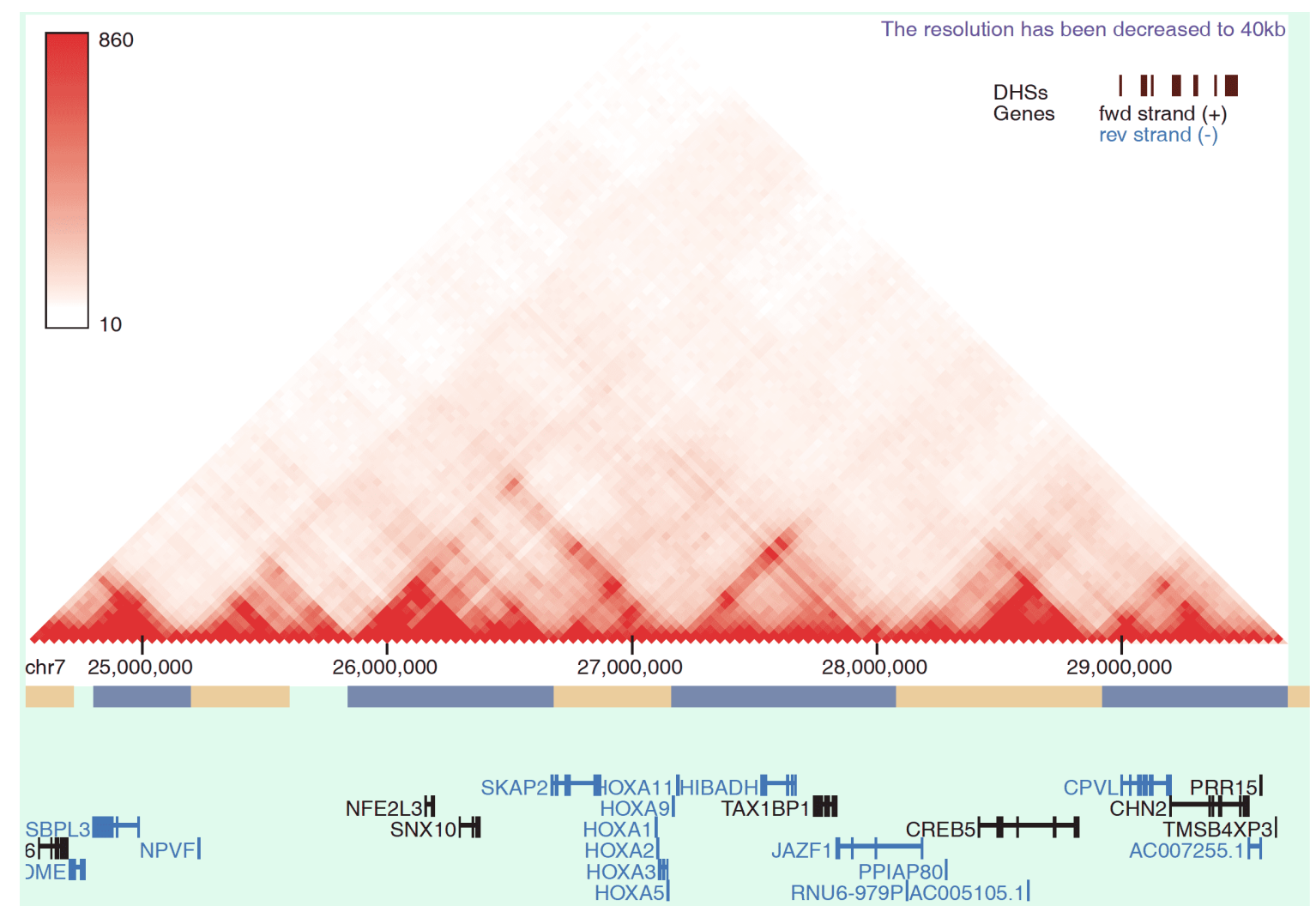

图 $2 H o x A$ 基因簇TAD热图(3dBrowser). 使用3D基因组汶览器汶览Hi-C数据的示例, 展示了 HOXA1基因在GM12878细胞系 中的Hi-C相互作用热图，分辨率为 $40 \mathrm{~kb}$. 黄色和蓝色交替显示的横条是预测的TAD; 正向基因用黑色字体显示，反向基因用 蓝色字体显示

Figure 2 A heatmap of TAD for HoxA cluster (from 3dBrowser). The 3dBrowser screen shot for an example of Hi-C interaction heatmap for HOXA1 in GM12878, at a resolution of $40 \mathrm{~kb}$. The yellow and blue bars represent the different predicted TADs. The genes on the sense strand are in black, and the antisense in blue

维结构处于动态变化的过程, 众多因素参与调控 ${ }^{[20]}$. 处于不同分化阶段的细胞，其染色体也都具有独特的 三维构象. 多种疾病的基因组在三维构象上也存在异 常. 三维基因组学是当前基因组学相关研究的一个热 点, 人们在三维基因组结构与基因表达调控关系以及 三维结构测定等方面，取得了一系列的成果. 近年来, 已有一系列综述分别总结三维基因组的基本组织原 则 ${ }^{[21 ~ 23]}$; 三维基因组结构与基因调控 ${ }^{[24,25]}$ 、细胞命运

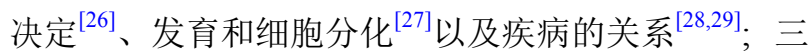
维基因组结构的检测技术与分析方法等 ${ }^{[30,31]}$. 而本文 则是聚焦在三维基因组结构的影响因素上，包括一维 基因组层面上的DNA序列及其共价修饰、与顺式调 控元件相结合的蛋白复合体、核小体排布与组蛋白修 饰以及在有丝分裂和染色体多倍化等过程中特有的染 色体结构等多个方面. 通过总结这些因素对染色体三 维结构的影响及其研究现状, 从而揭示染色体三维结
构研究的重要作用, 展望染色体三维结构将来的应用 前景.

\section{2 染色质三维结构影响因素}

\subsection{DNA序列}

一维的线性DNA序列包括基因结构与调控序列 等, 在一定程度上决定了三维基因组的结构, 是三维基 因组形成的物质基础. 人类蛋白编码基因序列(proteincoding sequences)约 20000 个, 在全基因组中所占的比 例不足 $2 \%$; 而其余的部分则是非编码序列(non-coding sequences). 非编码序列中包括大量的顺式调控元件 (cis-regulatory DNA elements, CRE). 顺式调控元件是 染色质高级结构的作用点, 通过与反式作用因子 (trans-acting factors)共同作用，参与基因表达的调 控 $^{[32]}$. 顺式调控元件包含启动子、增强子、沉默子、 
绝缘子等, 这些元件在不同的细胞类型和发育阶段选 择性发挥作用, 将基因组包装成一个动态的、合适的 染色体构象. 启动子 (promoter) 多位于转录起始位点 (transcription start site, TSS)的上游, RNA聚合酶与启 动子结合, 调控基因在时空上的表达 ${ }^{[33]}$. 与启动子不 同, 增强子(enhancer)是一段可加强基因转录的DNA序 列, 且调控作用可发生在距离靶基因数千碱基乃至 $1 \mathrm{Mb}$ 以上的位置, 甚至是不同的染色体之间 ${ }^{[34,35]}$. 超 级增强子是许多增强子形成的具有强突出作用的增强 子簇 ${ }^{[36]}$, 在阶段性发育中起调控作用. 超级增强子会 影响染色体的核组织状态, 局部浓缩调控蛋白 ${ }^{[37]}$.

哺乳动物的基因组中启动子约有40000 110000

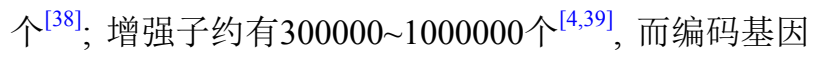
数目远远小于这些调控序列. 因此, 单个基因的表达, 受到多个顺式调控元件和反式作用因子的共同调控, 这种情况非常普遍. 人类基因组中存在大量的增强子 和启动子的相互作用, 例如远端增强子和近端启动子 形成染色质环结构，使得增强子向启动子区靠拢，二 者接触激活基因的转录 ${ }^{[40,41]}$. 同时近端和远端基因也 可通过启动子和启动子之间的相互作用协同表达 ${ }^{[42]}$.

沉默子(silencer)是基因表达的负调控元件, 能够 对基因的表达起阻遏作用 ${ }^{[43]}$. 在酿酒酵母中, 沉默子 可以促进异染色质的组装, 将异染色质隔绝在特定的 区域, 限制其扩散能力 ${ }^{[44]}$, 同时沉默子还可以促进染 色质成环等其他构象, 增进染色质的组装过程, 如果 没有沉默子存在, 异染色质结构的稳定性会受到影 响 ${ }^{[45]}$.

绝缘子(insulator)能够隔绝无关增强子和沉默子, 保证转录过程中信息传递的精准调控 ${ }^{[46]}$. 越来越多的 证据表明, 绝缘子在染色体结构域中起积极作用, 能 够维持和保护染色体结构域边界 ${ }^{[4]}$. 绝缘子位点间的 相互作用也可以改变染色质三维构象: 两个绝缘子相 互作用形成染色质环结构, 使得增强子和启动子处在 同一个环内, 拉近增强子和启动子在三维空间上的距 离, 促进基因表达 ${ }^{[48]}$; 或者将启动子和增强子隔离, 阻 止转录的发生 ${ }^{[49]}$. 绝缘子发生改变会造成染色质三维 结构的改变, 已经有研究表明这种异常与癌症有关 ${ }^{[50]}$. 除了顺式调控元件之间的相互作用以外, 启动子与外 显子也可成环, 改变这种相互作用可以产生不同的剪

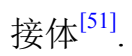

顺式调控元件之所以能被反式作用因子识别, 是
因为其含有反式作用因子结合所识别的信息, 如转录 因子结合位点(transcription factor binding sites, TFBS). 例如转录因子CTCF(CCCTC binding factor, CTCF)结 合位点在染色质成环过程中起关键作用. 如果缺失 CTCF位点, 染色质三维结构将改变, 染色质相互作用 随之受到影响 ${ }^{[52]}$. 研究显示, CTCF结合位点在基因组 上具有方向性，这种方向性决定了染色质环化的方向， 进而影响染色质相互作用 ${ }^{[33]}$. 该研究采用最新的基因 组编辑和Hi-C测序技术, 通过直接改变特定的关键 DNA序列信息, 最终改变三维基因组的结构, 这进一 步肯定了一维基因组序列确实是三维基因组结构的基 础. CTCF结合位点中的碱基突变也会影响染色质的拓 扑结构 ${ }^{[54]}$.

除顺式调控元件外，非编码序列还包括重复序列 (repeated sequences或repetitive elements). DNA重复序 列在基因进化和基因重组中扮演着重要的角色. 有观 点认为, 重复序列的配对是染色质高级结构组织的驱 动力, 可驱动染色质的定点折叠和染色质交联 ${ }^{[5]}$. DNA重复序列可形成新的TAD, 研究人员发现, SOX 基因的不同的重复序列会造成不同的表型 ${ }^{[56}$.

而非编码序列的另一种产物—— lncRNA(long non-coding RNA), 也可招募转录因子或与靶基因作用, 形成染色质环结构或特定的亚核结构, 调控转录的起 始以及X染色体失活 ${ }^{[57]}$. 沉默的X染色体转录产生的 IncRNA—Xist(X-inactive specific transcript), 可导致 $\mathrm{X}$ 染色体三维结构的重排，从而定位到基因沉默区的 核纤层 ${ }^{[58]}$. 非编码序列ThymoD可改变染色体的三维 结构, 影响增强子Bcl11b在核内的定位, 调控免疫反 应，小鼠体内 ThymoD的缺失会导致淋巴瘤等多种疾

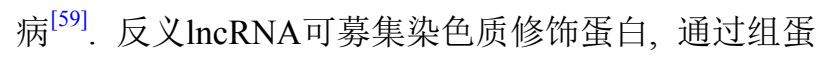
白修饰或DNA甲基化等导致染色质结构的变化 ${ }^{[60]}$. 在 $\operatorname{lncRNA}$ 与染色质分离的过程中, 也可能伴随着局部核 组织和细胞状态的变化 ${ }^{[61]}$. 此外增强子的转录产物 - RNA(enhancer RNA), 能够促进增强子和启动子 成环, 调控基因表达 ${ }^{[62]}$.

染色质区室A中基因密度高于染色质区室B, 两者 的结构也存在较大差异. 相比结构紧密的区室B, 区室 $\mathrm{A}$ 的结构较为松散, 更有利于基因的转录 ${ }^{[63]}$.

\subsection{DNA共价修饰}

甲基化和羟甲基化是两种最常见的DNA共价修 
饰形式. 大量研究表明，DNA甲基化与基因表达调 控、异染色质的形成、基因组稳定性密切相关，是胚 胎发育、细胞分化以及疾病发生过程中最为重要的表 观调控因素之一 ${ }^{[64-66]}$. 传统的理论认为, DNA甲基化 的主要功能是抑制基因的表达 ${ }^{[67]}$. 启动子或增强子区 域的DNA甲基化可能会导致甲基识别蛋白招募特异 性重塑因子, 产生闭合的染色质结构, 阻止转录机器的 接近 ${ }^{[68]}$; CTCF结合位点的甲基化会抑制 CTCF蛋白的 结合而影响染色质环的形成 ${ }^{[69]}$. 而最近的一系列体内 外的研究表明, TFBS的甲基化也会促进很多转录因子 的结合 ${ }^{[70 \sim 73]}$.

此外，DNA甲基化还会直接影响DNA的成环作用 与 $\mathrm{TAD}$ 的形成. 高甲基化区域中的稀疏低甲基化 $\mathrm{CpG}$ (sparse conserved under-methylated $\mathrm{CpG}, \mathrm{scUMC}$ )与组 织染色质三维结构的 4 个染色质环因子有关. 染色质环 因子在增强子和启动子相互作用中起牵引作用，维持 增强子-启动子环结构. $\mathrm{scUMC}$ 甲基化程度的变化会引 起染色质环因子与靶序列结合强度的改变 ${ }^{[74]}$. 在 $I D H I$ 突变的胶质瘤中, $\mathrm{CTCF}$ 结合位点的甲基化减少了 $\mathrm{CTCF}$ 蛋白的结合, 引起TAD边界的模糊甚至消失, 由 此导致原癌基因 $P D G F R A$ 的启动子与其他基因的增强 子形成染色质环，发生相互作用，激活PDGFRA的表 达 ${ }^{[50]}$. 近年来, 研究人员还通过DNA甲基化定向编辑 技术(dCas9-Tet1和dCas9-Dnmt3a)特异性地改变CTCF 结合位点的甲基化状态, 从而改变了 CTCF介导形成的 染色质环，这是DNA甲基化影响染色质成环的最直接 证明 ${ }^{[75]}$.

在三维基因组更大的层级结构单元上(如染色质 区室)，DNA甲基化同样起重要的调控作用. 活跃区室 $\mathrm{A}$ 中的启动子和增强子等顺式调控元件区域常处于低 甲基化状态, 相关基因趋向于表达 ${ }^{[17]}$. 而当区室A向区 室B进行转换时, 调控元件的甲基化程度不断增高, 基 因表达也随之下调. 研究还发现, 胚胎发育早期基因组 甲基化模式与区室高度相关 ${ }^{[76]}$. 更大范围的, 如整条 $\mathrm{X}$ 染色体的失活，也与DNA甲基化密不可分. 通常认为, 在DNA甲基化、组蛋白的修饰和XIST的表达以及其 他因子的共同作用下, X染色体异染色质化, 从而失活; 而DNA甲基化进一步维持了这种失活状态 ${ }^{[77]}$.

DNA 甲基化还与基因组的稳定性密切相关. 研究 表明, DNA低甲基化可引起杂合性丢失(loss of heterozygosity，LOH)发生的频率上升，易发生染色体易位，
增加染色体的不稳定性 ${ }^{[78]}$. 通常情况下，基因组中的 重复序列处于高甲基化状态 ${ }^{[79]}$; 而在某些状态下, 比 如癌症发生时，一部分重复序列元件甲基化程度会降 低, 从而导致染色质重组的发生频率上升, 进一步导 致染色质区域的去浓缩化.

DNA 甲基化与胚胎发育、细胞分化、细胞命运 决定等密切相关，研究也发现不同的细胞其甲基化模 式具有细胞特异性 ${ }^{[80]}$. 而这些不同甲基化模式与三维 基因组结构的具体关系也引起研究人员的兴趣. 随着 单细胞测序技术的不断进步, 研究人员开发出了在单 细胞水平同时测定全基因组DNA甲基化水平和染色 质三维结构的方法 ${ }^{[11,82]}$, 这使得DNA甲基化与三维基 因组结构关系的研究更加精细化. 这些方法结合了Hi$\mathrm{C} / 3 \mathrm{C}$ 和全基因组亚硫酸盐测序(whole-genome bisulfite sequencing, WGBS), 在单细胞水平上研究DNA甲基化 的状态与染色质状态之间的相关性. 其中任兵课题 组 ${ }^{[81]}$ 开发的技术为scMethyl-HiC(single-cell Methyl$\mathrm{HiC}$ ), 他们在小鼠胚胎干细胞(mouse embryonic stem cells, mESC)中应用此技术发现, DNA甲基化水平在染 色质环两端和 TAD 内都具有高度相关性, 使用 scMethyl-HiC产生的DNA甲基化数据可以明显把两种 培养条件下的 $\mathrm{mESC}$ 聚成三类，提示 $\mathrm{mESC}$ 的异质性. 而Echer课题组 ${ }^{[82]}$ 开发的方法为 sn-m3C-seq(single-nucleus methyl-3C sequencing), 利用该技术, 研究人员获 得了超过 4200 个人类大脑的前额叶皮层细胞的甲基化 和3C数据, 这些细胞涵盖了14种不同的皮质细胞类型, 而这些细胞类型之间的差异性染色质互作与差异性甲 基化区域以及 CTCF结合位点的差异性甲基化密切 相关.

\section{3 基因结构单元(基因与启动子等)结合蛋白复 合体}

真核生物的蛋白编码基因序列包括外显子与内含 子, 以及上游的启动子区域. 真核生物中, 全部的编码 RNA(messenger RNA, mRNA)和大部分的非编码RNA (non-coding RNAs, ncRNA)都是由RNA聚合酶 II (Pol II )转录产生的 ${ }^{[83]}$. 转录时, RNA聚合酶 II 要与多种转 录因子(transcription factors, TFs)、启动子与增强子等 顺式调控元件协调共同作用，形成特定的染色质结构 (图3). 人类基因组中编码转录因子的基因数目非常庞 大, 约占全部基因总数的 $8 \%{ }^{[84]}$. 这些TFs通过绑定到位 


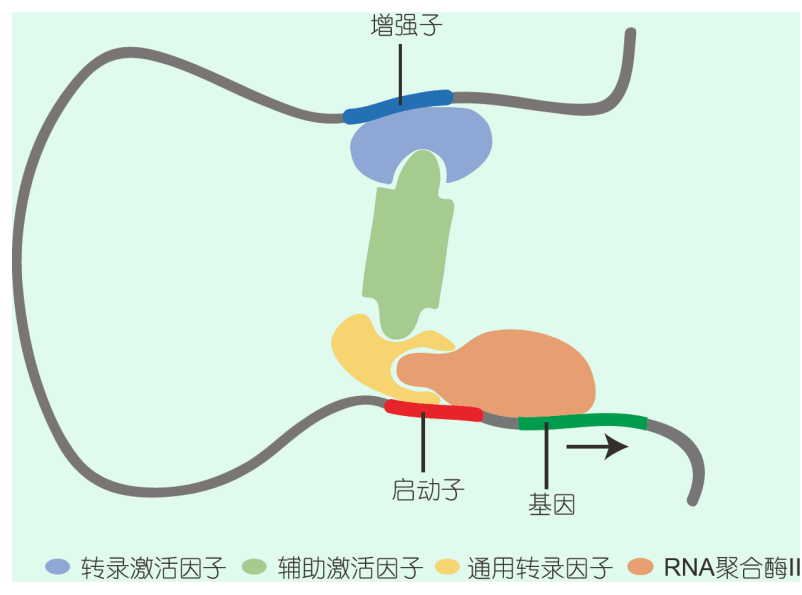

图 3 基因结构与基因结合蛋白复合体. 启动子和增强子形 成染色质环, 在转录起始复合物的作用下激活基因的转录

Figure 3 The gene structure and the transcription complex. The promoter and enhancer can form a chromatin loop, which could activate the transcription of target genes with the assistance of transcription initiation complex

于顺式调控元件的结合位点, 激活(transcription activator)或抑制(transcription repressor)转录. 参与该过程的 蛋白质多达数百种, 常聚集在一起形成相关的蛋白复 合体. 这些转录相关的蛋白复合体通过重塑染色质结 构或对组蛋白进行修饰，在染色质三维结构的形成和 维持方面起重要作用 ${ }^{[85]}$.

RNA聚合酶II 与通用转录因子 (general transcription factors, GTF; 包括转录起始因子TFIIA, TFIIB, TFIID，TFIIE，TFIIF和TFIIH)一起结合到核心启动子 区域(core promoter), 形成转录起始复合体(preinitiation complex, PIC). PIC形成后, 可进一步调控染色质结构, 保证启动子处于开放状态 ${ }^{[86]}$. 对与RNA聚合酶 II 相关 的全基因组染色质相互作用进行分析发现，在RNA聚 合酶 II 结合位点中, 有 $65 \%$ 与染色质相互作用有关, 这 意味着RNA聚合酶 II 与染色质环的形成有关 ${ }^{[42]}$. 更有 研究表明，RNA聚合酶 II 可以占据活化的增强子和超 级增强子位点, 介导增强子与目的基因启动子成环, 激活靶基因的表达 ${ }^{[36,87]}$.

各种特异性的转录因子一方面与DNA调控序列 结合(如增强子), 一方面与PIC相互作用，从而形成特 定的染色质三维结构, 与细胞命运决定密切相关. 例如 先锋转录因子可以打开紧密的异染色质结构 ${ }^{[8]}$. 转录 因子CTCF是细胞内普遍存在的结构蛋白，可与Cohe$\sin$ 结合, 维持染色体的三维结构 ${ }^{[89]}$. 果蝇中CTCF等结
构蛋白与 CTCF结合位点绑定，可募集辅助结构蛋

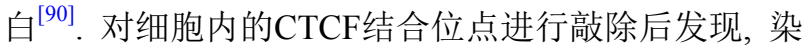
色质环的数目减少, 大小未发生改变, 染色体相互作用 发生改变 ${ }^{[91]}$. 而另一种转录因子ZNF143的结合位点与 CTCF的位点有所重合，说明ZNF143也可能与染色质 环的形成有关 ${ }^{[92]}$. 转录因子YY1可与自身形成二聚体, 与增强子和启动子结合, 以类似 CTCF的方式帮助染色 质形成环, 影响染色质的相互作用 ${ }^{[93]}$. 雌激素受体 $\alpha$ 在 靶基因周围形成二聚体或与FoxA1和RNAPII等其他 因子相互作用, 形成染色质环结构 ${ }^{[9]}$. 绝缘子元件及其 结合蛋白聚集在核中形成绝缘体. 绝缘体将绝缘子元 件募集起来形成染色质环，介导染色质之间的相互作 用，如果蝇的双胸复合体BX-C所包含的三个基因，受 到多个顺式调控元件和反式作用因子的精确调控. 其 中绝缘子Fab-8 与CTCF绝缘体蛋白相互作用形成绝缘 体发挥作用 ${ }^{[46]}$. 将绝缘子元件聚集成绝缘体可以是组 织染色质的手段.

转录因子行使功能时, 还常常伴随着辅助调控因 子(co-regulators)的共同参与. 对转录激活因子(activator)起调节作用的为辅助激活因子 (co-activator), 多种 辅助激活因子装配到一起, 形成辅助激活因子复合体 (co-activator complex). 这些蛋白复合体在基因转录中 的染色质结构重塑和维持过程中起至关重要的作 用 ${ }^{[94]}$. 转录中介复合物(mediator)是目前所知最大的辅 助激活因子复合体，由 33 个亚单位组成，包括MED1$31, \mathrm{CDK} 8$ 和 $c y c l i n \mathrm{C}^{[95]}$. 转录中介复合物是转录因子 与RNA聚合酶 II 转录机器之间的桥梁，通过招募通用 转录因子, 移除核小体(nucleosome), 维持启动子区域 的稳定性 ${ }^{[96]}$. 此外, 还有染色质重塑复合体(chromatin remodeling complex, 如SWI/SNF, CHD, Ino80 $0^{[97]}$ 等)和 组蛋白修饰复合体(histone-modification complex, 如甲 基化相关的 Set $1 / \mathrm{MLL}^{[98,99]}$ 和乙酰化相关的 CBP/ $\mathrm{p} 300^{[100]}$ 等). 此外, 转录过程对染色质三维结构也有影 响. 如果将转录过程持续下去, 可观察到Cohesin信号 减弱, 而区室 $\mathrm{A}$ 转为区室 $\mathrm{B}^{[101]}$. 这些复合体与转录因子 一起相互协调、共同塑造了转录时的染色质结构.

\section{4 基因簇结构(共线性)结合蛋白复合体}

基因家族(gene family), 是由一个基因通过基因重 复而产生的一组基因, 其序列相似, 功能相近. 多数时 候，同一家族的基因分散在同一染色体的不同位置或 
者分散在不同的染色体上. 而有些同家族的基因可以 紧密地排列在一起, 形成一个基因簇(gene cluster). 基 因簇中的基因数目少则数个, 多至上百个, 基因间通常 相距不超过数 $\mathrm{kb}^{[102]}$. 基因簇在不同的发育时期可以行 使不同的功能，目前已经发现多个基因簇的时空表达 与染色体三维结构有关，包括HOX基因簇、珠蛋白基 因簇等.

$H O X$ 家族 (图2)在脊椎动物肢体发育过程中呈现 共线性的方式, 分次表达. 发育过程中 $H O X$ 基因簇依次 活化 ${ }^{[103]}$. 这种发育过程中的分段式表达的调控由染色 质拓扑结构域的改变介导, $\mathrm{PcG}$ 蛋白复合体(Polycomb group, $\mathrm{PcG}$ )参与其中. $\mathrm{PcG}$ 为染色质修饰蛋白, 可抑制 基因的转录, 包括Polycomb抑制复合物 1 (Polycomb repressive complex 1, PRC1)和Polycomb抑制复合物2 (Polycomb repressive complex 2, PRC2). PcG蛋白复合 体可介导染色体间相互作用 ${ }^{[104]}$. PcG蛋白复合体通过 与 $H O X$ 基因调控区结合, 将 $H O X$ 基因所在片段形成异 染色质, 使得转录因子无法与调控区结合, 从而抑制 $H O X$ 基因的表达 ${ }^{[105]}$. 转录沉默的HoxA 基因簇被组织 成多个染色质环, 染色质环化是转录沉默的Hox 基因 簇的主要特征. 除了 $\mathrm{PcG}$ 在 $H O X$ 基因簇的染色质成环 中起外作用, CTCF也可能通过二聚化介导Hox基因簇 形成正确的三维结构 ${ }^{[106]}$.

与 $P c G$ 蛋白复合体作用相反的是 $T r x G$ 蛋白复合体 (Trithorax group), 它能够消除PcG蛋白的作用, 对于基 因的活跃状态起维持作用 ${ }^{[107]}$. TrxG蛋白包括染色质重 塑复合物 SWI/SNF等, 能够改变组蛋白修饰和核小体 占位状态, 介导染色质环化打开染色质 ${ }^{[108]}$.

\section{5 基因与基因簇形成的染色质空间结构}

如前面2.4部分所述, 基因簇之间很容易相互作用, 形成特定的染色质空间结构. 原钻粘蛋白 (protocadherin, Pcdh)在神经系统发育中起重要作用, 它有三个关 系密切的基因簇: $\alpha, \beta, \gamma$. 在小鼠中的研究发现, $\alpha$ 基因 簇中, $\mathrm{CTCF} / \mathrm{Cohesin}$ 与启动子和增强子的结合引起增 强子和启动子的环化 ${ }^{[109]}$. 珠蛋白基因簇包括五种: $\alpha$, $\beta, \gamma, \varepsilon, \delta$, 不同珠蛋白对应的基因簇, 在胚胎发育到成 人的不同阶段具有不同的表达量, 且有时空的精确性. 珠蛋白基因簇上存在多个转录因子结合位点, 不同转 录因子在特定的时空与转录因子结合位点结合, 与 $\mathrm{CTCF}$ 一起参与染色质构象的形成和变化 ${ }^{[110]}$. 果蝇体
内 Lam 基因簇的相邻基因可采用相同的染色质构象, 如组蛋白修饰标记的染色体结构域, 也可通过核纤层 调控染色质的区室化, 或共享增强子、启动子等元件 作为其共调控的基础 ${ }^{[111]}$.

除了基因簇之间发生的这种同源基因之间的相互 作用外, 不同的基因之间或者基因与基因簇之间, 也会 在DNA序列层面发生作用, 形成特定的三维基因组结 构. NANOG 基因就可以诱导其靶基因间(如 Klf2, Irx , Sall1)形成三维的转录因子枢纽(3D-hub), 该枢纽变成 一种障碍, 从而维持多能干细胞的干性 ${ }^{[26,112]}$. 有研究 表明, 共调控基因(co-regulated genes)也会成簇出现, 形成转录热点. 比如, 一部分Met4的靶基因之间也会 形成这种染色质三级结构 ${ }^{[113]}$.

\section{6 核小体空间占位与组蛋白共价修饰状态}

真核生物中，DNA缠绕组蛋白(histones)八聚体形 成的核小体(nucleosome)是染色质的基本结构. 组蛋白 八聚体有4种核心组蛋白 $(\mathrm{H} 2 \mathrm{~A}, \mathrm{H} 2 \mathrm{~B}, \mathrm{H} 3, \mathrm{H} 4)$, 核小体 DNA长度约 $147 \mathrm{bp}$. 核小体在基因组上的位置是动态 变化的，如果启动子区域在核小体中，常会抑制基因 转录 ${ }^{[114]}$. 而组蛋白的多种共价修饰, 如甲基化、乙酰 化、磷酸化、泛素化等, 能够改变核小体的位置, 影响 核小体与DNA的结合状态 ${ }^{[115]}$, 同时组蛋白包含多个变 体, 这些因素都会影响染色质的结构, 保证染色质有序 的动态变化.

核小体占位(nucleosome occupancy)或占位移除也 是影响基因转录调控的重要因素. 研究表明, 核小体占 位的形成和在染色质的精准定位是真核基因表达所必 需的 ${ }^{[116]}$. 在TSS周围, 转录因子可以与核小体竞争结 合调控位点, 使核小体的分布在基因组上发生动态变 化, 调节染色质可及性 ${ }^{[117]}$. 这种竞争性作用可发生在 多个转录因子和核小体之间, 且需要一定的空间, 染色 质局部三维结构可能变得松散以容纳转录因子 ${ }^{[118,119]}$. 当基因处于激活状态时, TSS周围形成核小体非占位 区域(nucleosome free region, NFR), 使转录因子和转 录机器可以接近 ${ }^{[114]}$. 高度转录基因的 TSS下游, 往往 会观察到周期性的核小体排位(nucleosome positioning), 数个核小体依次排列 ${ }^{[120]}$. 有研究表明, 核小体排 位与小鼠胚胎干细胞的分化与发育密切相关 ${ }^{[121]}$, 并且 观察到在细胞分化过程中, 核小体排位的变化介导了 DNA甲基化/去甲基化和 CTCF的结合 ${ }^{[122]}$. 
染色体相互作用过程与局部染色质结构关系密 切, 该过程中核小体占位也会发生改变. 常染色质和异 染色质中核小体之间的距离远近不同, 研究表明, 组蛋 白H1与异染色质的形成有关 ${ }^{[117,123]}$, 如果 $\mathrm{H} 1$ 组蛋白缺 失, 核小体间距离缩短. 因此, 通过核小体位置可以预 测染色质的相互作用 ${ }^{[124]}$. 对酵母中全基因组的核小体 间距进行分析发现，不规则的核小体的间距造成局部 $3 \mathrm{D}$ 组织的差异, 通过核小体的占位可以准确地预测 $3 \mathrm{D}$ 结构的结构域边界等 ${ }^{[125]}$. 核小体与核小体之间的相互 作用有助于染色质结构域形成并限制其动力学, 与 $\mathrm{Co}-$ hesin一起构成染色体结构域 ${ }^{[126]}$.

组蛋白修饰与基因表达调控密切相关 ${ }^{[127,128]}$, 例如 H3K4me1，H3K4me3，H3K27ac等是基因激活的标志, 而H3K9me3, H3K27me3 等则是基因抑制的标志 ${ }^{[129]}$. 其中, $\mathrm{H} 3 \mathrm{~K} 4 \mathrm{me} 1$ 主要分布在增强子区域, $\mathrm{H} 3 \mathrm{~K} 4 \mathrm{me} 3$ 聚 集在转录基因的启动子区域, 而 $\mathrm{H} 3 \mathrm{~K} 27 \mathrm{ac}$ 则在转录基 因的启动子和增强子区域都可以发现. 组蛋白修饰对 于染色质三维结构的形成也起关键作用. 对Hox基因 家族成员 $\mathrm{BX}-\mathrm{C}$ 的研究中发现, TAD 的边界存在 H3K27me3修饰的分界线, H3K27me3修饰的区域有其 独特的 TAD结构域, 该结构域内的基因将会沉默 ${ }^{[130]}$. 并且H3K27me3有助于异染色质蛋白HP1 $\alpha$ 维持异染色 质结构域 ${ }^{[131]}$. 组蛋白乙酰化与染色质的可接近性有 关 ${ }^{[132]}$, 乙酰化高低程度也代表染色质不同的活性状 态, 绝缘子两侧组蛋白乙酰化程度的高低差别明显, 说明组蛋白的乙酰化与绝缘子维持染色质的分界有 关 $^{[133]}$, 组蛋白乙酰化同时可募集染色质重塑复合体和 转录因子, 通过组蛋白修饰可以调控染色质结构域和 动力学 ${ }^{[126]}$. 超级增强子可与 $\mathrm{H} 3 \mathrm{~K} 4 \mathrm{me} 3$ 在染色质的相 互作用调控中共同发挥作用，说明 $\mathrm{H} 3 \mathrm{~K} 4 \mathrm{me} 3$ 也参与了 染色质结构的变化 ${ }^{[134]}$.

核心组蛋白有多种变体, 组蛋白变体所在染色体 区域与常规组蛋白所在染色体区域的结构通常有明显 不同. 其中 $\mathrm{H} 2 \mathrm{~A}$ 的变体 $\mathrm{H} 2 \mathrm{~A} . \mathrm{Z}$ 可以增强与邻近核小体 H4的相互作用从而影响染色质的折叠和稳定. H2A.Z 可影响基因启动子区的染色质结构, 促进由异染色质 蛋白HP1 $\alpha$ 介导的染色质纤维的折叠 ${ }^{[135]}$, 因此H2A.Z 在基因转录激活和细胞周期中有重要作用. 研究人员 在酵母中发现, H2A.Z与常染色质与端粒结构边界的 形成有关, 染色质边界具有 H2A.Z富集现象 ${ }^{[136]}$. $\mathrm{MacroH} 2 \mathrm{~A}$ 变体存在于脊椎动物中的失活 $\mathrm{X}$ 染色体, 这
说明MacroH2A 与异染色质的压缩有关 ${ }^{[137]}$; H2A.Bbd 则存在于另一条没有失活的 $\mathrm{X}$ 染色体中, 与基因的转 录激活和松散染色质有关 ${ }^{[138]}$. H3 组蛋白具有 5 种变体, 其中H3.3变体与常染色质相关, 富含与转录激活有关 的修饰, 能够阻碍染色质的折叠效应 ${ }^{[139]}$, 着丝粒部位 的核小体 (含有H3组蛋白变体CENP-A)与常规核小体 结构不同, 通过改变CENP-A的残基组成, 可以形成截 然不同的两种染色体结构, CENP-A对于维持着丝粒 部位的染色质结构起重要作用 ${ }^{[140]}$.

染色质的组装过程需要组蛋白伴侣的参与. 组蛋 白伴侣与组蛋白结合, 协助组蛋白折叠, 形成特定的 染色质结构. 酵母体内组蛋白分子伴侣FACT可与核 小体中H2B结合, 破坏核小体间的相互作用, 导致染 色质高级结构稳定性减弱, 结构变松散, 促进基因转

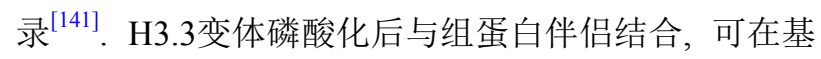
因组上的重复区域建立异染色质. 四核小体结构是 30 $\mathrm{nm}$ 染色质纤维动态折叠过程中的一个稳定的中间态 结构单元 ${ }^{[142]}$, 而组蛋白分子伴侣FACT可以通过负调 控四核小体结构的稳定性进行基因表达的调控 ${ }^{[141]}$.

\section{7 染色体结构域与细胞核内结构单元的关系}

细胞核是存储染色质的细胞器, 由核膜将其与细 胞质分离开, 此外细胞核内还含有核仁等结构. 每条 染色体在细胞核内有各自特有的染色体疆域. 这些染 色体疆域又进一步分隔成不同而又相对独立的染色体 结构域(chromatin domain), 构成基因转录所需的微环 境. 依据检测方法和在细胞核内所占据空间的不同, 这 些染色质结构域(图4)主要分为拓扑相关结构域、核 纤层相关结构域(lamina-associated domains, LADs)和 核仁相关结构域(nucleolus-associated domains, NADs $)^{[143]}$.

采用Hi-C技术, 任兵课题组 ${ }^{[14]}$ 最早发现并命名了 $\mathrm{TAD} . \mathrm{TAD}$ 是染色质三维层级结构中重要的一层, 居 于区室A/B和染色质环之间, 是染色质结构的一个重 要单元. 与 $\mathrm{LAD}$ 和 $\mathrm{NAD}$ 不同, $\mathrm{TAD}$ 在细胞核内广泛存 在, 并不直接与细胞核内的特定结构直接作用, 属于 自我相互作用类型 (TAD内部作用强, TAD间作用 弱 ${ }^{[144]}$. 鉴于前文已对TAD进行了大量描述, 本节主要 关注 $\mathrm{LAD}$ 和NAD, 以及 $\mathrm{TAD}$ 与它们的关系.

核膜下方存在由核纤层蛋白组成的支撑结构核纤层 ${ }^{[145]}$, 其在核内部形成一层保护壳. 哺乳动物细 


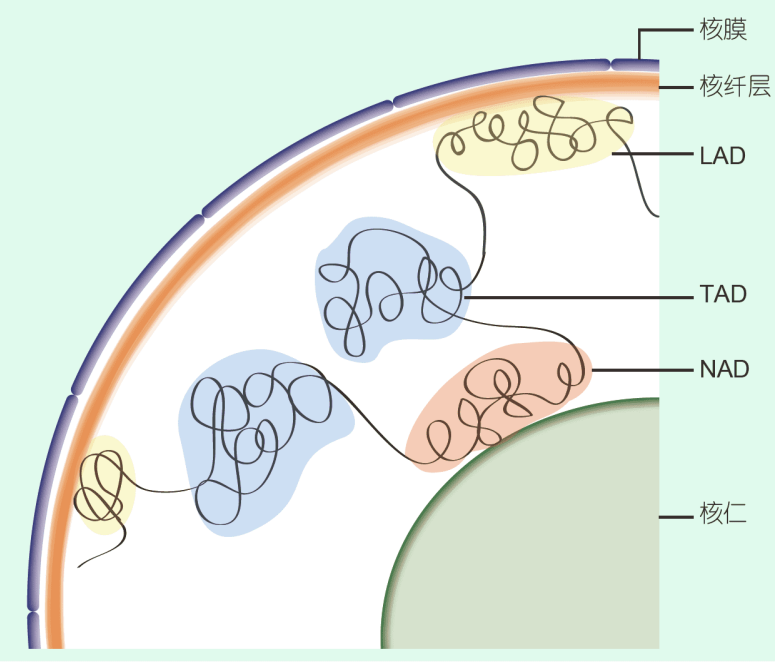

图 4 染色体结构域: LAD, NAD与TAD

Figure 4 The chromatin domains: LAD, NAD and TAD

胞内基因组与细胞核周围的核纤层网络相关联．核纤 层与染色质的组织和基因表达有关，研究发现，核纤 层可作为染色质和核膜的“桥”，将染色质固定到核膜 上 $^{[111]}$. 采用DamID技术, 研究人员在果蝇、小鼠和人 类细胞中鉴定了染色质中与核纤层特定结合的结构 $-\mathrm{LADs}^{[146]}$. 每个LAD大小约0.1 10 $\mathrm{Mb}^{[22]}$, 而全部 LAD序列大约占基因组的 $35 \%{ }^{[147]}$. LADs与区室B十分 接近, 都位于核纤层区域, 主要是异染色质, 二者基因 大部分都处在不转录的沉默状态，而区室A则主要位 于核内部(图4) ${ }^{[148]}$. LADs与TADs有所关联, TADs范围 内包含部分LADs, 二者部分重合 ${ }^{[14,149]}$. 在LADs的边 界处富含 CTCF位点和 $\mathrm{CpG}$ 位点，提示CTCF，DNA甲 基化以及启动子结构可能对 $\mathrm{LAD}$ 的形成有一定的影 响 ${ }^{[146]}$.

核纤层的基本结构蛋白是核纤层蛋白，能够建立 和维持 $3 \mathrm{D}$ 染色质构型，在不同物种中种类也不相同， 人体内包括核纤层蛋白 $\mathrm{A}, \mathrm{B}, \mathrm{C}^{[150]}$. 核纤层蛋白 $\mathrm{A} / \mathrm{C}$ 和 核纤层蛋白受体的缺失会造成位于核外周的异染色质 缺失和核内部的异染色质倒置 ${ }^{[151]}$. 核纤层蛋白通过 LADs对基因组三维结构进行调节，使得不同活性 TADs之间的相互作用得以维持. 丢失核纤层蛋白，对 TADs的整体没有影响，但是会影响TAD之间的相互作 用，将LADs从核纤层上解离会打断LADs和内部染色 质的相互作用 ${ }^{[152,153]}$. TADs的染色质类型与其在核内 的定位密切相关, 活性低的TADs优先结合核纤层成为
LADs, 因此更倾向于位于核外周部位 ${ }^{[154,155]}$.

细胞核中的核仁区域是合成核糖体RNA(ribosomal RNA, rRNA)的场所. 通过核仁提取、纯化并测定 与之结合的DNA片段，Németh等人 ${ }^{[156]}$ 在全基因组范 围内鉴定了NADs(图4). NADs约占全基因组的4\%, 是 富含沉默基因的染色质区域 ${ }^{[156,157]}$. 有丝分裂后不迁移 到核外周的LADs可能与核仁的NADs 有关 ${ }^{[158]}$. 在酵母 和果蝇研究中发现, 减少rRNA的基因数量, 会改变异 染色质的组织结构 ${ }^{[159]}$.

细胞核内类似于细胞骨架的纤维网络为核基质, 由核纤层蛋白和其他蛋白组成 ${ }^{[160]}$. 敲低核基质蛋白 HNRNPU，会导致非LADs和LADs之间进行转换，区 室和TAD内的远距离调控也会发生改变, 因此核基质 对三维基因组也具有组织和维持作用 ${ }^{[161]}$.

\section{8 细胞有丝分裂过程}

真核生物中, 细胞通过有丝分裂(mitosis)一分为 二, 是细胞增殖的主要方式. 细胞进行有丝分裂时, 染 色体形态会经历巨大的变化, 从松散的染色质经历压 缩包装转变成缩短的染色体结构 ${ }^{[162]}$. 有丝分裂具有细 胞周期性(cell cycle), 主要分为分裂间期(interphase)、 前期(prophase)、中期(metaphase)、后期(anaphase)和 末期(telophase) 5 个阶段. 分裂间期时长约占整个细胞 周期的 $90 \%$ $95 \%$, 此时母细胞中的染色体通过DNA复 制(S期)进行加倍, 为分裂前期形成姐妹染色单体做好 准备. 间期染色体的三维结构如前所述, 主要包括区 室、TADs和染色质环等. 其中染色质环是最为基础的 结构(图5), 根据Hi-C和Capture-C等技术所测得的三维 基因组中染色质间的相互作用, 研究人员提出“环挤压 模型”(loop extrusion model)来解释环的形成 ${ }^{[163,164]}$. 在 该模型中, 环状蛋白复合物Cohesin中的分子马达能牵 引、挤压DNA进入此蛋白质复合体环. DNA不断被挤 压，直到两端都遇到边界元件(主要是CTCF结合位点， 且具有方向性)所结合的边界分子(CTCF), DNA不能 再进一步被挤压, 形成相对稳定的染色质环 ${ }^{[165]}$. 染色 质环对TAD的形成与TAD内部分子的相互作用, 以及 染色质的进一步浓缩非常重要.

姐妹染色单体在有丝分裂后期开始分离, 为细胞 分裂做准备 ${ }^{[166]}$, 用 $5 \mathrm{C}$ 技术对细胞周期中的染色质三 维结构进行检测, 发现在有丝分裂中期, 区室A/B和 $\mathrm{TAD}$ 消失，染色质进一步压缩 ${ }^{[167]}$. 分裂期的染色体更 


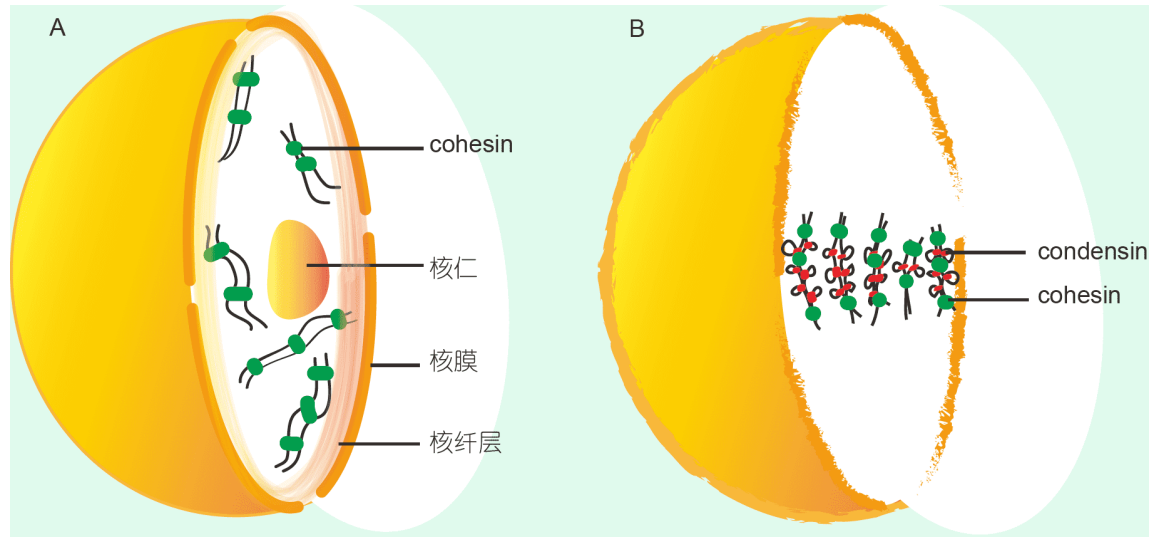

图 5 间期和有丝分裂期的 TAD形成差异. cohesin在细胞周期间期(A), cohesin和condensin在有丝分裂期(B), 二者介导不同的 结构域形成

Figure 5 The differences of TAD formation between interphase and mitosis. Cohesin during interphase (A) and cohesin and condensin during mitosis (B), which mediate the formations of different domains

加致密，其压缩过程也与染色质环的形成相关，“环挤 压”同样存在(图5). 与间期不同的是，此时的环更大也 更紧密，而介导这个过程的主要是凝聚素蛋白复合体 (Condensins), 而不是Cohesin复合体(图5). 凝聚素蛋白 可分为凝聚素蛋白 I 和凝聚素蛋白 II, 二者在有丝分 裂的不同时期发挥不同的作用，影响染色质的浓缩结 构. 凝聚素蛋白 II 在有丝分裂前期参与染色质浓缩, 凝聚素蛋白 I 有助于染色体臂的解离和纵向染色体的 浓缩, 使有丝分裂顺利进入下一阶段 ${ }^{[168]}$. 酵母中, 细胞 进行有丝分裂时，凝聚素蛋白和Cohesin蛋白都介导了 TADs的形成. 需要说明的是, Cohesin在细胞周期的 S 期和M期都起作用，通过CTCF结合位点等调控序列， 将姐妹染色单体“黏”在一起，从而影响染色质环和 TADs的形成 ${ }^{[169]}$. 不过, Cohesin介导的TADs相对较小, 一般小于 $50 \mathrm{~kb}$. 而凝聚素蛋白所介导的TAD结构则更 大更远，常常是 $300 \mathrm{~kb} \sim 1 \mathrm{Mb}$ 的范围，这有助于染色体 在细胞的 $\mathrm{M}$ 期形成更致密的三维结构 ${ }^{[170]}$. 另外, 染色 质重塑复合物 SWI/SNF 的亚基ARIDIA 与凝聚素蛋 白 II 结合帮助染色质区室B的形成，在有丝分裂间期 调节染色质的分区，敲除ARID1A会造成区室发生转 换 ${ }^{[171]}$.

绝大部分高等生物的生命开始于精子和卵子融合 形成受精卵，而精子和卵子的形成(也称配子发生)则 是通过减数分裂(meiosis)来保证子代与亲代个体染色 体数目的一致性. 研究发现, 精子和卵子两者的染色体 结构截然不同. 小鼠的卵母细胞在成熟过程中, TAD和
区室不断减弱直至消失; 精子则与之不同, 随着精子的 成熟, 细胞中出现类 $\mathrm{TAD}$ 和类区室 $\mathrm{A} / \mathrm{B}$ 的结构, 且存在 更多的远距离的染色质相互作用，这个过程可能与 DNA的复制有关 ${ }^{[20,172]}$. 在受精卵形成后，其会经历染 色体重塑的过程, 重新折叠成复杂的高级结构.

\section{9 多倍体化后细胞有丝分裂变化}

哺乳动物和鸟类等高等生物, 都是二倍体生物(diploid), 其体细胞内含有两套染色体组. 目前已经在单 细胞水平上解析出二倍体的染色体三维结构 ${ }^{[173]}$. 细胞 进行有丝分裂时，会将复制产生的DNA平均分配到两 个子细胞中去. 而如果有丝分裂受阻或者不均匀分裂, 可能在新的子细胞中发生多于两套染色体组的情况, 即多倍体化(polyploidization). 多倍体(polyploid)可以 产生新的物种, 在生物进化过程中非常重要, 尤其在 植物中普遍存在.

目前，对多倍体植物有丝分裂时三维基因组的研 究还比较有限. 最近对拟南芥四倍体的染色体构象进 行分析发现，与二倍体相比，四倍体拟南芥染色体间 的相互作用增加，近距离染色质间相互作用减少，染 色体的多倍体化可能改变了染色质环和组蛋白修饰, 从而影响了染色质的三维结构. 但每条染色体仍独立 存在，具有其 CT结构，类区室 $\mathrm{A} / \mathrm{B}$ 的结构在二倍体和 四倍体间也比较相似 ${ }^{[174]}$. 四倍体的棉花基因组中区室 $\mathrm{A} / \mathrm{B} 、 \mathrm{TAD}$ 的状态与二倍体相比也有所不同 ${ }^{[175]}$.

与植物不同, 动物中多倍体现象非常少见, 只是在 
果蝇、非洲爪蛻 ${ }^{[176]}$ 等低等生物中偶有发生. 在果蝇的 研究中发现, 多倍体也可重新进入有丝分裂, 但是染色 体的复制不完整，异染色质部分丢失，影响其正常分 裂，增加染色体畸变频率 ${ }^{[177]}$. 果蝇的保育细胞(nurse cells)中，凝聚素 II 与多线性染色体和异染色质的分离 有关，凝聚素 II 可抑制同源配对和染色体的相互作用 从而使染色体分离, 诱导染色体疆域的形成 ${ }^{[178]}$.

尽管高等动物不是多倍体生物, 但高等动物的某 些细胞或特定情况下 (比如癌症)也会发生多倍体

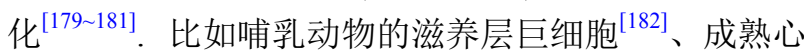
肌细胞 ${ }^{[183]}$ 等. 小鼠滋养层巨细胞(trophoblast giant cells, TGCs)具有多倍体细胞核，由二倍体的滋养层干 细胞(trophoblast stem cells, TSCs)分化而来. 对TSCs向 TGCs分化过程中的染色质结构进行研究后发现, 随着 分化程度的加深, TSCs染色质中组蛋白变体H2AX和 H3.3的水平逐渐增加，二者均会增加核小体的不稳定 性, 核小体逐渐变得松散. 在这个过程中, 参与控制染 色质结构的组蛋白伴侣多样性降低. 而意外的是, 虽然 核小体变得松散，但是TGCs中的异染色质却是增加 的, H1组蛋白可能在其中扮演了重要的角色. TGCs中 组蛋白变体的独特组合建立了特征性的染色质结构, 这使得大量的DNA能够精确地包装在细胞核中并产 生独特的基因表达 ${ }^{[182]}$.

\section{3 问题与展望}

近年来，一系列结合 $3 \mathrm{C}$ 技术和测序技术的方法应 用于三维基因组学领域, 使人们对三维基因组学的认 识有了很大的进步, 如三维基因组结构的层级学说, 环挤压模型等基本原理性的概念不断被引入到三维基 因组学的研究中. 这些研究进一步证明, 细胞核内发生 的动态变化是极其精密复杂的过程. 这个过程中DNA 序列及其修饰、转录因子、RNA聚合酶、结构蛋 白、组蛋白修饰及组蛋白变体都扮演着重要角色. 尽 管取得了一系列成果，仍有许多问题亟待解决，主要 的问题和研究方向包括以下 5 个方面.

(1) RNA在三维基因组中的作用. 目前三维基因 组学的研究主要集中在DNA和DNA、蛋白质和 DNA、蛋白质和蛋白质之间相互作用，而对于另外一 个生物大分子—RNA相关的研究相对较少. 最近, GRID-Seq的开发 ${ }^{[184]}$, 让研究人员可以在全基因组范
围内研究RNA与染色质的相互作用. 另外, 已经有不 同的方法可以同时测定RNA与蛋白质 ${ }^{[185]}$ 、DNA与蛋 白质 ${ }^{[186]}$ 的相互作用. 期待有新的方法可以同时测定 DNA, RNA与蛋白三者之间的相互结合.

（2）4D基因组一一时间维度. 科学家们早就意识 到基因组的结构不仅仅是空间位置，还包含了时间因 素，基因组在细胞内的空间结构和时间变化共同保证 了细胞生长发育的有序进行. 2015年, 国际合作项目 “四维细胞核组学计划”启动 ${ }^{[187]}$, 就是要探讨这个问 题. 随着技术进步以及测序成本的下降，得到细胞生 长分化时一系列不同时间的三维基因组结构的动态变 化成为可能.

（3）单细胞层面. 单细胞测序技术的发展也让人 们把目光转向了染色体三维基因组的异质性. $\mathrm{TAD}$ 结 构在单细胞水平被进一步证实 ${ }^{[188]}$. 此外, 在单细胞层 面同时研究多种因素对基因组三维结构的影响也成为 可能. 比如Methyl-HiC 就能在单细胞水平同时测定全 基因组DNA甲基化水平和染色质三维结构.

(4) 新技术方法的引入与结合. 最典型的应用就 是基因编辑技术与三维基因组学的结合 ${ }^{[3]}$, 让人们可 以在单碱基水平或者转录因子结合位点水平来研究 DNA序列对基因组三维结构的影响. 最近开发的ChromEMT, 结合了分子标记技术与断层电子显微镜扫描 成像技术 ${ }^{[189]}$, 可以动态地观察染色质的变化, 为人们 研究三维基因组学打开了更多的视角.

(5) 数据的标准化与整合. 目前, 各种三维基因组 学方法产生了海量的数据, 而这些数据的解读尚缺乏 统一的标准, 这也使得不同数据间的比较与整合更加 困难. 而这些数据又如何在一个系统里友好地展示给 用户 ${ }^{[190]}$, 也同样是个巨大的挑战. 这些成为计算三维 基因组学或生物信息学亟待解决的问题.

如上所述, 三维基因组学确实还有一系列的问题 需要探索. 尽管人们并不能一时很快给出这些问题的 答案, 随着研究的深入, 科学家们已经开始探讨三维 基因组学在疾病中的应用前景. 例如肿瘤中染色体结 构与正常染色体存在巨大的差异，染色体的不稳定性 以及多倍体的存在、染色体重排的高频率和断裂都说 明在肿瘤中三维基因组结构发生了重大变化，如何有 效利用这一变化对肿瘤进行诊断研究和治疗, 是需要 考虑的问题. 在糖尿病模型的小鼠肝细胞中染色质重 塑和多倍性也有所上升 ${ }^{[191]}$. 此外, 神经疾病中也存在 
错误的染色体折叠模式 ${ }^{[192]}$. 众多的研究结果都向人们 展示了三维基因组在疾病诊治研究中的巨大潜力. 目 前对于染色体三维结构的研究还在持续进行当中，随
着技术的不断进步和研究的不断深入，利用三维基因 组学的研究成果来对疾病进行诊断和治疗, 并非遥不 可及的事情.

致谢感谢华中科技大学金晶博士在本文准备过程中给出的意见、建议和支持; 感谢华中科技大学研究生刘晓昭和石 雪妍女士在本文插图制作过程中提供的帮助.

\section{参考文献}

1 Lodish H, Berk A, Kaiser C A, et al. Molecular cell biology. Washington: Macmillan, 2008

2 Li G, Ruan Y, Gu R. Emergence of 3D genomics. Chin Sci Bull, 2014, 59: 1165-1172

3 Institute N H G R. The Human Genome Project completion: Frequently Asked Questions. 2013

4 Consortium E P. An integrated encyclopedia of DNA elements in the human genome. Nature, 2012, 489: 57-74

5 Dekker J, Rippe K, Dekker M, et al. Capturing chromosome conformation. Science, 2002, 295: 1306-1311

6 Simonis M, Klous P, Splinter E, et al. Nuclear organization of active and inactive chromatin domains uncovered by chromosome conformation capture-on-chip (4C). Nat Genet, 2006, 38: 1348-1354

7 Dostie J, Richmond T A, Arnaout R A, et al. Chromosome conformation capture carbon copy (5C): A massively parallel solution for mapping interactions between genomic elements. Genome Res, 2006, 16: 1299-1309

8 Lieberman-Aiden E, van Berkum N L, Williams L, et al. Comprehensive mapping of long-range interactions reveals folding principles of the human genome. Science, 2009, 326: 289-293

9 Fullwood M J, Liu M H, Pan Y F, et al. An oestrogen-receptor- $\alpha$-bound human chromatin interactome. Nature, 2009, 462: 58-64

10 Schoenfelder S, Furlan-Magaril M, Mifsud B, et al. The pluripotent regulatory circuitry connecting promoters to their long-range interacting elements. Genome Res, 2015, 25: 582-597

11 Mifsud B, Tavares-Cadete F, Young A N, et al. Mapping long-range promoter contacts in human cells with high-resolution capture Hi-C. Nat Genet, 2015, 47: 598-606

12 Boveri T. Über Beziehungen des Chromatins zur Geschlechts-Bestimmung. 1909

13 Cremer T, Cremer C. Chromosome territories, nuclear architecture and gene regulation in mammalian cells. Nat Rev Genet, 2001, 2: 292-301

14 Dixon J R, Selvaraj S, Yue F, et al. Topological domains in mammalian genomes identified by analysis of chromatin interactions. Nature, 2012, 485: $376-380$

15 Rao S S P, Huntley M H, Durand N C, et al. A 3D map of the human genome at kilobase resolution reveals principles of chromatin looping. Cell, 2014, 159: 1665-1680

16 Cremer T, Cremer M. Chromosome territories. Cold Spring Harbor Perspect Biol, 2010, 2: a003889

17 Dixon J R, Jung I, Selvaraj S, et al. Chromatin architecture reorganization during stem cell differentiation. Nature, 2015, 518: 331-336

18 Kadauke S, Blobel G A. Chromatin loops in gene regulation. Biochim Biophys Acta, 2009, 1789: 17-25

19 Bonev B, Cavalli G. Organization and function of the 3D genome. Nat Rev Genet, 2016, 17: 661-678

$20 \mathrm{Ke} \mathrm{Y,} \mathrm{Xu} \mathrm{Y,} \mathrm{Chen} \mathrm{X,} \mathrm{et} \mathrm{al.} \mathrm{3D} \mathrm{chromatin} \mathrm{structures} \mathrm{of} \mathrm{mature} \mathrm{gametes} \mathrm{and} \mathrm{structural} \mathrm{reprogramming} \mathrm{during} \mathrm{mammalian} \mathrm{embryogenesis.} \mathrm{Cell,}$ 2017, 170: 367-381.e20

21 Rowley M J, Corces V G. Organizational principles of 3D genome architecture. Nat Rev Genet, 2018, 19: 789-800 Gibcus J H, Dekker J. The hierarchy of the 3D genome. Mol Cell, 2013, 49: 773-782 Yu M, Ren B. The three-dimensional organization of mammalian genomes. Annu Rev Cell Dev Biol, 2017, 33: 265-289 Schoenfelder S, Fraser P. Long-range enhancer-promoter contacts in gene expression control. Nat Rev Genet, 2019, 20: 437-455 van Steensel B, Furlong E E M. The role of transcription in shaping the spatial organization of the genome. Nat Rev Mol Cell Biol, 2019, 20: $327-337$ 
Chakraborty A, Ay F. The role of 3D genome organization in disease: From compartments to single nucleotides. Semin Cell Dev Biol, 2019, 90: 104-113

30 Risca V I, Greenleaf W J. Unraveling the 3D genome: Genomics tools for multiscale exploration. Trends Genets, 2015, 31: 357-372

31 Schmitt A D, Hu M, Ren B. Genome-wide mapping and analysis of chromosome architecture. Nat Rev Mol Cell Biol, 2016, 17: 743-755

32 Wittkopp P J, Kalay G. Cis-regulatory elements: Molecular mechanisms and evolutionary processes underlying divergence. Nat Rev Genet, 2012, 13: 59-69

33 Consortium E P, Birney E, Stamatoyannopoulos J A. Identification and analysis of functional elements in $1 \%$ of the human genome by the ENCODE pilot project. Nature, 2007, 447: 799-816

34 Bulger M, Groudine M. Looping versus linking: Toward a model for long-distance gene activation. Genes Dev 1999, 13: 2465-2477

35 Spilianakis C G, Lalioti M D, Town T, et al. Interchromosomal associations between alternatively expressed loci. Nature, 2005, 435: 637-645

Whyte W A, Orlando D A, Hnisz D, et al. Master transcription factors and mediator establish super-enhancers at key cell identity genes. Cell, 2013, 153: 307-319

37 Sabari B R, Dall'Agnese A, Boija A, et al. Coactivator condensation at super-enhancers links phase separation and gene control. Science, 2018, 361: eaar3958

38 Consortium F, Clst R P. A promoter-level mammalian expression atlas. Nature, 2014, 507: 462-470

39 Shen Y, Yue F, McCleary D F, et al. A map of the cis-regulatory sequences in the mouse genome. Nature, 2012, 488: 116-120

40 Sanyal A, Lajoie B R, Jain G, et al. The long-range interaction landscape of gene promoters. Nature, 2012, 489: 109-113

41 Jin F, Li Y, Dixon J R, et al. A high-resolution map of the three-dimensional chromatin interactome in human cells. Nature, 2013, 503: 290-294

$42 \mathrm{Li} \mathrm{G}$, Ruan X, Auerbach R K, et al. Extensive promoter-centered chromatin interactions provide a topological basis for transcription regulation. Cell, 2012, 148: 84-98

43 Ogbourne S, Antalis T M. Transcriptional control and the role of silencers in transcriptional regulation in eukaryotes. Biochem J, 1998, 331: 114

44 Lynch P J, Rusche L N. A silencer promotes the assembly of silenced chromatin independently of recruitment. Mol Cell Biol, 2009, 29: 43-56

45 Rusche L N, Lynch P J. Assembling heterochromatin in the appropriate places: A boost is needed. J Cell Physiol, 2009, 219: 525-528

46 Yang J, Corces V G. Chromatin insulators: A role in nuclear organization and gene expression. Adv Cancer Res 2011, 110: 43-76

47 Byrd K, Corces V G. Visualization of chromatin domains created by the gypsy insulator of Drosophila. J Cell Biol, 2003, 162: 565-574

48 Zhao H, Dean A. Organizing the genome: Enhancers and insulators. Biochem Cell Biol, 2005, 83: 516-524

$49 \mathrm{Xu}$ Z, Wei G, Chepelev I, et al. Mapping of INS promoter interactions reveals its role in long-range regulation of SYT8 transcription. Nat Struct Mol Biol, 2011, 18: 372-378

50 Flavahan W A, Drier Y, Liau B B, et al. Insulator dysfunction and oncogene activation in IDH mutant gliomas. Nature, 2016, 529: 110-114

51 Ruiz-Velasco M, Kumar M, Lai M C, et al. CTCF-mediated chromatin loops between promoter and gene body regulate alternative splicing across individuals. Cell Syst, 2017, 5: 628-637.e6

52 Espitia Jaimes C, Fish R J, Neerman-Arbez M. Local chromatin interactions contribute to expression of the fibrinogen gene cluster. J Thromb Haemost, 2018, 16: 2070-2082

53 Guo Y, Xu Q, Canzio D, et al. CRISPR inversion of CTCF sites alters genome topology and enhancer/promoter function. Cell, 2015, 162: 900910

54 Tang Z, Luo O J, Li X, et al. CTCF-mediated human 3D genome architecture reveals chromatin topology for transcription. Cell, 2015, 163: $1611-1627$

55 Tang S J. Chromatin organization by repetitive elements (CORE): A genomic principle for the higher-order structure of chromosomes. Genes, 2011, 2: 502-515

56 Franke M, Ibrahim D M, Andrey G, et al. Formation of new chromatin domains determines pathogenicity of genomic duplications. Nature, 2016, 538: 265-269 
57 Böhmdorfer G, Wierzbicki A T. Control of chromatin structure by long noncoding RNA. Trends Cell Biol, 2015, 25: 623-632

58 Engreitz J M, Ollikainen N, Guttman M. Long non-coding RNAs: Spatial amplifiers that control nuclear structure and gene expression. Nat Rev Mol Cell Biol, 2016, 17: 756-770

59 Isoda $\mathrm{T}$, Moore A J, He Z, et al. Non-coding transcription instructs chromatin folding and compartmentalization to dictate enhancer-promoter communication and $\mathrm{T}$ cell fate. Cell, 2017, 171: 103-119.e18

60 Magistri M, Faghihi M A, St Laurent Iii G, et al. Regulation of chromatin structure by long noncoding RNAs: Focus on natural antisense transcripts. Trends Genets, 2012, 28: 389-396

61 Melé M, Rinn J L. "Cat's cradling" the 3D genome by the act of lncRNA transcription. Mol Cell, 2016, 62: 657-664

62 Li X, Fu X D. Chromatin-associated RNAs as facilitators of functional genomic interactions. Nat Rev Genet, 2019, 20: 503-519

63 Stevens T J, Lando D, Basu S, et al. 3D structures of individual mammalian genomes studied by single-cell Hi-C. Nature, 2017, 544: 59-64

64 Bird A P. CpG-rich islands and the function of DNA methylation. Nature, 1986, 321: 209-213

65 Reik W, Dean W, Walter J. Epigenetic reprogramming in mammalian development. Science, 2001, 293: 1089-1093

66 Lister R, Mukamel E A, Nery J R, et al. Global epigenomic reconfiguration during mammalian brain development. Science, 2013, 341: 1237905

67 Schübeler D. Function and information content of DNA methylation. Nature, 2015, 517: 321-326

68 Dor Y, Cedar H. Principles of DNA methylation and their implications for biology and medicine. Lancet, 2018, 392: 777-786

69 Wang H, Maurano M T, Qu H, et al. Widespread plasticity in CTCF occupancy linked to DNA methylation. Genome Res, 2012, 22: 1680-1688

70 Mann I K, Chatterjee R, Zhao J, et al. CG methylated microarrays identify a novel methylated sequence bound by the CEBPB|ATF4 heterodimer that is active in vivo. Genome Res, 2013, 23: 988-997

71 Rishi V, Bhattacharya P, Chatterjee R, et al. CpG methylation of half-CRE sequences creates C/EBP $\alpha$ binding sites that activate some tissuespecific genes. Proc Natl Acad Sci USA, 2010, 107: 20311-20316

72 Chatterjee R, He X, Huang D, et al. High-resolution genome-wide DNA methylation maps of mouse primary female dermal fibroblasts and keratinocytes. Epigenets Chromatin, 2014, 7: 35

73 Yin Y, Morgunova E, Jolma A, et al. Impact of cytosine methylation on DNA binding specificities of human transcription factors. Science, 2017, 356: eaaj2239

74 Lin X, Su J, Chen K, et al. Sparse conserved under-methylated CpGs are associated with high-order chromatin structure. Genome Biol, 2017, 18: 163

75 Liu X S, Wu H, Ji X, et al. Editing DNA methylation in the mammalian genome. Cell, 2016, 167: 233-247.e17

76 Zhang Y, Xiang Y, Yin Q, et al. Dynamic epigenomic landscapes during early lineage specification in mouse embryos. Nat Genet, 2018, 50: 96105

77 Sharp A J, Stathaki E, Migliavacca E, et al. DNA methylation profiles of human active and inactive X chromosomes. Genome Res, 2011, 21: $1592-1600$

78 Eden A, Gaudet F, Waghmare A, et al. Chromosomal instability and tumors promoted by DNA hypomethylation. Science, 2003, $300: 455$

79 Ehrlich M. DNA methylation in cancer: Too much, but also too little. Oncogene, 2002, 21: 5400-5413

80 Bauer M. Cell-type-specific disturbance of DNA methylation pattern: A chance to get more benefit from and to minimize cohorts for epigenome-wide association studies. Int J Epidemiol, 2018, 47: 917-927

81 Li G, Liu Y, Zhang Y, et al. Joint profiling of DNA methylation and chromatin architecture in single cells. Nat Methods, 2019, 16: 991-993

82 Lee D S, Luo C, Zhou J, et al. Simultaneous profiling of 3D genome structure and DNA methylation in single human cells. Nat Methods, 2019, 16: 999-1006

83 Nikolov D B, Burley S K. RNA polymerase II transcription initiation: A structural view. Proc Natl Acad Sci USA, 1997, 94: 15-22

84 Lambert S A, Jolma A, Campitelli L F, et al. The human transcription factors. Cell, 2018, 172: 650-665

85 Narlikar G J, Fan H Y, Kingston R E. Cooperation between complexes that regulate chromatin structure and transcription. Cell, 2002, 108: 475487

86 Cook P R, Marenduzzo D. Transcription-driven genome organization: A model for chromosome structure and the regulation of gene expression tested through simulations. Nucleic Acids Res, 2018, 46: 9895-9906

87 Kagey M H, Newman J J, Bilodeau S, et al. Mediator and cohesin connect gene expression and chromatin architecture. Nature, 2010, 467: 430435 
88 Mayran A, Drouin J. Pioneer transcription factors shape the epigenetic landscape. J Biol Chem, 2018, 293: 13795-13804

89 Sanborn A L, Rao S S P, Huang S C, et al. Chromatin extrusion explains key features of loop and domain formation in wild-type and engineered genomes. Proc Natl Acad Sci USA, 2015, 112: E6456-E6465

$90 \mathrm{Xu}$ C, Corces V G. Towards a predictive model of chromatin 3D organization. Semin Cell Dev Biol, 2016, 57: 24-30

91 Rosa-Garrido M, Chapski D J, Schmitt A D, et al. High-resolution mapping of chromatin conformation in cardiac myocytes reveals structural remodeling of the epigenome in heart failure. Circulation, 2017, 136: 1613-1625

92 Ye B Y, Shen W L, Wang D, et al. ZNF143 is involved in CTCF-mediated chromatin interactions by cooperation with cohesin and other partners. Mol Biol, 2016, 50: 431-437

93 Weintraub A S, Li C H, Zamudio A V, et al. YY1 is a structural regulator of enhancer-promoter loops. Cell, 2017, 171: 1573-1588.e28

94 Krasnov A N, Mazina M Y, Nikolenko J V, et al. On the way of revealing coactivator complexes cross-talk during transcriptional activation. Cell Biosci, 2016, 6: 15

95 Poss Z C, Ebmeier C C, Taatjes D J. The Mediator complex and transcription regulation. Crit Rev Biochem Mol Biol, 2013, 48: 575-608

96 Nock A, Ascano J M, Barrero M J, et al. Mediator-regulated transcription through the +1 nucleosome. Mol Cell, 2012, 48: 837-848

97 Bornelöv S, Reynolds N, Xenophontos M, et al. The nucleosome remodeling and deacetylation complex modulates chromatin structure at sites of active transcription to fine-tune gene expression. Mol Cell, 2018, 71: 56-72.e4

98 Vicent G P, Nacht A S, Font-Mateu J, et al. Four enzymes cooperate to displace histone H1 during the first minute of hormonal gene activation. Genes Dev, 2011, 25: 845-862

99 Cheng X. Structural and functional coordination of DNA and histone methylation. Cold Spring Harbor Perspect Biol, 2014, 6: a018747

100 Jin Q, Yu L R, Wang L, et al. Distinct roles of GCN5/PCAF-mediated H3K9ac and CBP/p300-mediated H3K18/27ac in nuclear receptor transactivation. EMBO J, 2011, 30: 249-262

101 Heinz S, Texari L, Hayes M G B, et al. Transcription elongation can affect genome 3D structure. Cell, 2018, 174: 1522-1536.e22

102 Yi G, Sze S H, Thon M R. Identifying clusters of functionally related genes in genomes. Bioinformatics, 2007, 23: 1053-1060

103 Chambeyron S, Bickmore W A. Chromatin decondensation and nuclear reorganization of the HoxB locus upon induction of transcription. Genes Dev, 2004, 18: 1119-1130

104 Tiwari V K, Cope L, McGarvey K M, et al. A novel 6C assay uncovers Polycomb-mediated higher order chromatin conformations. Genome Res, 2008, 18: 1171-1179

105 Ferraiuolo M A, Rousseau M, Miyamoto C, et al. The three-dimensional architecture of Hox cluster silencing. Nucleic Acids Res, 2010, 38: $7472-7484$

106 Andrey G, Montavon T, Mascrez B, et al. A switch between topological domains underlies HoxD genes collinearity in mouse limbs. Science, 2013, 340: 1234167

107 Simon J A, Tamkun J W. Programming off and on states in chromatin: Mechanisms of Polycomb and trithorax group complexes. Curr Opin Genets Dev, 2002, 12: 210-218

108 Schuettengruber B, Martinez A M, Iovino N, et al. Trithorax group proteins: Switching genes on and keeping them active. Nat Rev Mol Cell Biol, 2011, 12: 799-814

109 Guo Y, Monahan K, Wu H, et al. CTCF/cohesin-mediated DNA looping is required for protocadherin $\alpha$ promoter choice. Proc Natl Acad Sci USA, 2012, 109: 21081-21086

110 Zhou G L, Xin L, Song W, et al. Active chromatin hub of the mouse $\alpha$-globin locus forms in a transcription factory of clustered housekeeping genes. Mol Cell Biol, 2006, 26: 5096-5105

111 Pickersgill H, Kalverda B, de Wit E, et al. Characterization of the Drosophila melanogaster genome at the nuclear lamina. Nat Genet, 2006, 38: 1005-1014

112 Jeter C R, Liu B, Lu Y, et al. NANOG reprograms prostate cancer cells to castration resistance via dynamically repressing and engaging the AR/ FOXA1 signaling axis. Cell Discov, 2016, 2: 16041

113 Du M, Bai L. 3D clustering of co-regulated genes and its effect on gene expression. Curr Genet, 2017, 63: 1017-1021

114 Jiang C, Pugh B F. Nucleosome positioning and gene regulation: Advances through genomics. Nat Rev Genet, 2009, 10: 161-172

115 Bartke T, Vermeulen M, Xhemalce B, et al. Nucleosome-interacting proteins regulated by DNA and histone methylation. Cell, 2010, 143: 470484 
$116 \mathrm{Hu} \mathrm{Z}$, Chen K, Xia Z, et al. Nucleosome loss leads to global transcriptional up-regulation and genomic instability during yeast aging. Genes Dev, 2014, 28: 396-408

117 Klemm S L, Shipony Z, Greenleaf W J. Chromatin accessibility and the regulatory epigenome. Nat Rev Genet, 2019, 20: 207-220

118 Moyle-Heyrman G, Tims H S, Widom J. Structural constraints in collaborative competition of transcription factors against the nucleosome. J Mol Biol, 2011, 412: 634-646

119 He X, Chatterjee R, John S, et al. Contribution of nucleosome binding preferences and co-occurring DNA sequences to transcription factor binding. BMC Genomics, 2013, 14: 428

120 Schones D E, Cui K, Cuddapah S, et al. Dynamic regulation of nucleosome positioning in the human genome. Cell, 2008, 132: 887-898

121 Teif V B, Vainshtein Y, Caudron-Herger M, et al. Genome-wide nucleosome positioning during embryonic stem cell development. Nat Struct Mol Biol, 2012, 19: 1185-1192

122 Teif V B, Beshnova D A, Vainshtein Y, et al. Nucleosome repositioning links DNA (de)methylation and differential CTCF binding during stem cell development. Genome Res, 2014, 24: 1285-1295

123 Diesinger P M, Heermann D W. Depletion effects massively change chromatin properties and influence genome folding. Biophys J, 2009, 97: $2146-2153$

124 Zhang H, Li F, Jia Y, et al. Characteristic arrangement of nucleosomes is predictive of chromatin interactions at kilobase resolution. Nucleic Acids Res, 2017, 45: 12739-12751

125 Wiese O, Marenduzzo D, Brackley C A. Nucleosome positions alone can be used to predict domains in yeast chromosomes. Proc Natl Acad Sci USA, 2019, 116: 17307-17315

126 Nozaki T, Imai R, Tanbo M, et al. Dynamic organization of chromatin domains revealed by super-resolution live-cell imaging. Mol Cell, 2017, 67: 282-293.e7

127 Vastenhouw N L, Schier A F. Bivalent histone modifications in early embryogenesis. Curr Opin Cell Biol, 2012, 24: 374-386

128 Dong X, Weng Z. The correlation between histone modifications and gene expression. Epigenomics, 2013, 5: 113-116

129 Bernstein B E, Mikkelsen T S, Xie X, et al. A bivalent chromatin structure marks key developmental genes in embryonic stem cells. Cell, 2006, 125: $315-326$

130 Mateo L J, Murphy S E, Hafner A, et al. Visualizing DNA folding and RNA in embryos at single-cell resolution. Nature, 2019, 568: 49-54

131 Boros J, Arnoult N, Stroobant V, et al. Polycomb repressive complex 2 and H3K27me3 cooperate with H3K9 methylation to maintain heterochromatin protein $1 \alpha$ at chromatin. Mol Cell Biol, 2014, 34: 3662-3674

132 Allis C D, Jenuwein T. The molecular hallmarks of epigenetic control. Nat Rev Genet, 2016, 17: 487-500

133 Lutz M, Burke L J, Barreto G, et al. Transcriptional repression by the insulator protein CTCF involves histone deacetylases. Nucleic Acids Res, 2000, 28: $1707-1713$

134 Cao F, Fang Y, Tan H K, et al. Super-enhancers and broad H3K4me3 domains form complex gene regulatory circuits involving chromatin interactions. Sci Rep, 2017, 7: 2186

135 Fan J Y, Rangasamy D, Luger K, et al. H2A.Z alters the nucleosome surface to promote HP1 $\alpha$-mediated chromatin fiber folding. Mol Cell, 2004, 16: 655-661

136 Zlatanova J, Thakar A. H2A.Z: View from the top. Structure, 2008, 16: 166-179

137 Avner P, Heard E. X-chromosome inactivation: Counting, choice and initiation. Nat Rev Genet, 2001, 2: 59-67

138 Tremethick D J. Higher-order structures of chromatin: The elusive $30 \mathrm{~nm}$ fiber. Cell, 2007, 128: 651-654

139 Kimmins S, Sassone-Corsi P. Chromatin remodelling and epigenetic features of germ cells. Nature, 2005, 434: 583-589

140 Fang J, Liu Y, Wei Y, et al. Structural transitions of centromeric chromatin regulate the cell cycle-dependent recruitment of CENP-N. Genes Dev, 2015, 29: 1058-1073

$141 \mathrm{Li} \mathrm{W}$, Chen P, Yu J, et al. FACT remodels the tetranucleosomal unit of chromatin fibers for gene transcription. Mol Cell, 2016, 64: 120-133

142 Song F, Chen P, Sun D, et al. Cryo-EM study of the chromatin fiber reveals a double helix twisted by tetranucleosomal units. Science, 2014, 344: $376-380$

143 Yamamoto T, Saitoh N. Non-coding RNAs and chromatin domains. Curr Opin Cell Biol, 2019, 58: 26-33

144 Pope B D, Ryba T, Dileep V, et al. Topologically associating domains are stable units of replication-timing regulation. Nature, 2014, 515: 402405 
145 Burke B, Stewart C L. The nuclear lamins: Flexibility in function. Nat Rev Mol Cell Biol, 2013, 14: 13-24

146 Guelen L, Pagie L, Brasset E, et al. Domain organization of human chromosomes revealed by mapping of nuclear lamina interactions. Nature, 2008, 453: 948-951

147 Wu F, Olson B G, Yao J. DamID-seq: Genome-wide mapping of protein-DNA interactions by high throughput sequencing of adeninemethylated DNA fragments. J Vis Exp, 2016, doi: 10.3791/53620

148 Kind J, Pagie L, de Vries S S, et al. Genome-wide maps of nuclear lamina interactions in single human cells. Cell, 2015, 163: 134-147

149 Robson M I, de Las Heras J I, Czapiewski R, et al. Constrained release of lamina-associated enhancers and genes from the nuclear envelope during T-cell activation facilitates their association in chromosome compartments. Genome Res, 2017, 27: 1126-1138

150 Colognato H, Yurchenco P D. Form and function: The laminin family of heterotrimers. Dev Dyn, 2000, 218: 213-234

151 Solovei I, Wang A S, Thanisch K, et al. LBR and lamin A/C sequentially tether peripheral heterochromatin and inversely regulate differentiation. Cell, 2013, 152: 584-598

152 Kim Y, Zheng X, Zheng Y. Role of lamins in 3D genome organization and global gene expression. Nucleus, 2019, 10: 33-41

153 Zheng X, Hu J, Yue S, et al. Lamins organize the global three-dimensional genome from the nuclear periphery. Mol Cell, 2018, 71: 802-815.e7

154 Ciabrelli F, Cavalli G. Chromatin-driven behavior of topologically associating domains. J Mol Biol, 2015, 427: 608-625

155 Leemans C, van der Zwalm M C H, Brueckner L, et al. Promoter-intrinsic and local chromatin features determine gene repression in LADs. Cell, 2019, 177: 852-864.e14

156 Németh A, Conesa A, Santoyo-Lopez J, et al. Initial genomics of the human nucleolus. PLoS Genet, 2010, 6: e1000889

157 van Koningsbruggen S, Gierlinski M, Schofield P, et al. High-resolution whole-genome sequencing reveals that specific chromatin domains from most human chromosomes associate with nucleoli. Mol Biol Cell, 2010, 21: 3735-3748

158 Kind J, Pagie L, Ortabozkoyun H, et al. Single-cell dynamics of genome-nuclear lamina interactions. Cell, 2013, 153: 178-192

159 Picart-Picolo A, Picault N, Pontvianne F. Ribosomal RNA genes shape chromatin domains associating with the nucleolus. Nucleus, 2019, 10: $67-72$

160 Rynearson A L, Sussman C R. Nuclear structure, organization, and oncogenesis. J Gastrointest Canc, 2011, 42: 112-117

161 Fan H, Lv P, Huo X, et al. The nuclear matrix protein HNRNPU maintains 3D genome architecture globally in mouse hepatocytes. Genome Res, 2018, 28: 192-202

162 Vagnarelli P. Mitotic chromosome condensation in vertebrates. Exp Cell Res, 2012, 318: 1435-1441

163 Fudenberg G, Imakaev M, Lu C, et al. Formation of chromosomal domains by loop extrusion. Cell Rep, 2016, 15: 2038-2049

164 Kim Y, Shi Z, Zhang H, et al. Human cohesin compacts DNA by loop extrusion. Science, 2019, 366: 1345-1349

165 Splinter E, Heath H, Kooren J, et al. CTCF mediates long-range chromatin looping and local histone modification in the beta-globin locus. Genes Dev, 2006, 20: 2349-2354

166 Liang Z, Zickler D, Prentiss M, et al. Chromosomes progress to metaphase in multiple discrete steps via global compaction/expansion cycles. Cell, 2015, 161: 1124-1137

167 Naumova N, Imakaev M, Fudenberg G, et al. Organization of the mitotic chromosome. Science, 2013, 342: 948-953

168 Hirota T, Gerlich D, Koch B, et al. Distinct functions of condensin I and II in mitotic chromosome assembly. J Cell Sci, 2004, 117: 6435-6445

169 Murayama Y, Uhlmann F. Biochemical reconstitution of topological DNA binding by the cohesin ring. Nature, 2014, 505: 367-371

170 Tanizawa H, Kim K D, Iwasaki O, et al. Architectural alterations of the fission yeast genome during the cell cycle. Nat Struct Mol Biol, 2017, 24: 965-976

171 Wu S, Fatkhutdinov N, Rosin L, et al. ARID1A spatially partitions interphase chromosomes. Sci Adv, 2019, 5: eaaw5294

172 Flyamer I M, Gassler J, Imakaev M, et al. Single-nucleus Hi-C reveals unique chromatin reorganization at oocyte-to-zygote transition. Nature, 2017, 544: 110-114

173 Tan L, Xing D, Chang C H, et al. Three-dimensional genome structures of single diploid human cells. Science, 2018, 361: 924-928

174 Zhang H, Zheng R, Wang Y, et al. The effects of Arabidopsis genome duplication on the chromatin organization and transcriptional regulation. Nucleic Acids Res, 2019, 47: 7857-7869

175 Wang M, Wang P, Lin M, et al. Evolutionary dynamics of 3D genome architecture following polyploidization in cotton. Nat Plants, 2018, 4: 9097

176 Stooke-Vaughan G A, Davidson L A, Woolner S. Xenopus as a model for studies in mechanical stress and cell division. Genesis, 2017, 55: 
e23004

177 Fox D T, Gall J G, Spradling A C. Error-prone polyploid mitosis during normal Drosophila development. Genes Dev, 2010, 24: 2294-2302

178 Bauer C R, Hartl T A, Bosco G. Condensin II promotes the formation of chromosome territories by inducing axial compaction of polyploid interphase chromosomes. PLoS Genet, 2012, 8: e1002873

179 Assié G, Letouzé E, Fassnacht M, et al. Integrated genomic characterization of adrenocortical carcinoma. Nat Genet, 2014, 46: 607-612

180 Ganem N J, Storchova Z, Pellman D. Tetraploidy, aneuploidy and cancer. Curr Opin Genets Dev, 2007, 17: 157-162

181 Pampalona J, Frías C, Genescà A, et al. Progressive telomere dysfunction causes cytokinesis failure and leads to the accumulation of polyploid cells. PLoS Genet, 2012, 8: e1002679

182 Hayakawa K, Terada K, Takahashi T, et al. Nucleosomes of polyploid trophoblast giant cells mostly consist of histone variants and form a loose chromatin structure. Sci Rep, 2018, 8: 5811

183 Ponnusamy M, Li P F, Wang K. Understanding cardiomyocyte proliferation: An insight into cell cycle activity. Cell Mol Life Sci, 2017, 74: $1019-1034$

184 Li X, Zhou B, Chen L, et al. GRID-seq reveals the global RNA-chromatin interactome. Nat Biotechnol, 2017, 35: 940-950

185 Lunde B M, Moore C, Varani G. RNA-binding proteins: Modular design for efficient function. Nat Rev Mol Cell Biol, 2007, 8: 479-490

186 Evertts A G, Zee B M, Garcia B A. Modern approaches for investigating epigenetic signaling pathways. J Appl Physiol, 2010, 109: 927-933

187 Dekker J, Belmont A S, Guttman M, et al. The 4D nucleome project. Nature, 2017, 549: 219-226

188 Bintu B, Mateo L J, Su J H, et al. Super-resolution chromatin tracing reveals domains and cooperative interactions in single cells. Science, 2018, 362: eaau1783

189 Ou H D, Phan S, Deerinck T J, et al. ChromEMT: Visualizing 3D chromatin structure and compaction in interphase and mitotic cells. Science, 2017, 357: eaag0025

190 Zhou X, Maricque B, Xie M, et al. The human epigenome browser at Washington University. Nat Methods, 2011, 8: 989-990

191 Ghiraldini F G, Silva I S, Mello M L S. Polyploidy and chromatin remodeling in hepatocytes from insulin-dependent diabetic and normoglycemic aged mice. Cytometry, 2012, 81A: 755-764

192 Sun J H, Zhou L, Emerson D J, et al. Disease-associated short tandem repeats co-localize with chromatin domain boundaries. Cell, 2018, 175: 224-238.e15 


\title{
The impact factors of 3D genome organization
}

\author{
FAN YiXian ${ }^{1,2}$, HANG XiaoYi, ${ }^{1,2}$ \& HE XiMiao ${ }^{1,2}$ \\ 1 Department of Physiology, School of Basic Medicine, Tongji Medical College, Huazhong University of Science and Technology, \\ Wuhan 430030, China; \\ 2 Center for Genomics and Proteomics Research, School of Basic Medicine, Tongji Medical College, Huazhong University of Science and Technology, \\ Wuhan 430030, China
}

The 3D architecture of chromosomes is involved in the precision regulation of gene expression, and the changes in spatial conformation of chromosomes, accordingly, influence the biological processes in a cell. Recent findings in 3D genomics, through technological advances in approaches combining chromosome conformation capture (3C) and DNA sequencing, have greatly improved our understanding that how the chromatin is folded. The chromosomes are tightly packed in the nucleus with hierarchical structural units, and these units are influenced by many factors such as DNA sequence itself and the associated protein complex. In this review, we focus on the major impact factors of 3D genome organization, including the primary DNA sequences and the covalent modification of DNA (e.g. methylation); the protein complexes interplaying with gene structures and cis regulatory elements; nucleosome positioning and histone modifications; and how the structure of 3D genome changes in mitosis and polyploidization. We highlight the importance of 3D genome research by summarizing the current situation and progresses in studies of the impact factors of chromatin structure. We also discuss the critical challenges in the field, and propose the future directions as well as the potential applications in diseases.

\section{D genomics, chromatin spatial organization, transcription regulation, epigenetic modifications, mitosis}

doi: $10.1360 /$ SSV-2019-0218 